\title{
Mental Health Act Commission and the code of practice
}

\author{
P D ROHDE
}

I have followed the debate about the revision of the Mental Health Act 1959 and have now studied the Mental Health Act 1983 and its accompanying memorandum. I have tried to relate the debate to my own clinical practice in a district general hospital psychiatric unit. I am worried about the bureaucracy of the new Act, the fact that it will mean more form filling and assessments for me and other staff in the hospital, but I respect the motives behind the Act and understand that a safeguard for one person is extra work for another, and, therefore, I accept most of the new provisions. But by defining some areas more carefully-notably, grounds for detention and consent to treatment-the new Act has thrown into sharp relief the areas that are still not clear. I hope that the Minister for Health will deal with some of these points in the forthcoming code of practice.

\section{Right to treat}

Section 56 of the Act makes it clear that the provisions concerning consent to treatment do not apply (a) to patients detained under section 4, the emergency application equivalent to the old section $29,(b)$ to a person who is detained under section 5 , the equivalent of the old section 30 , or (c) to a person detained under section 136. Dimond has suggested that this was an apparent oversight in new statutory rules. ${ }^{1}$ If so it is a curious one, as for the other sections the rights to treat are spelt out in great detail. Staff, faced with a duty to detain patients but without any right to treat them, may turn to the memorandum to the Act, which states that these patients "are in the same position as informal patients with regard to treatment ... and common law rules apply." This is remarkably unhelpful. Most mental health professionals may not know what common law rules are, and to leave the position like this is to invite disagreements. I have been advised that "the common law defence applies only in emergencies where immediate action is necessary and where treatment is for the purpose of bringing that emergency to an end." If this is the government's view it would be helpful for the fact to be stated clearly in the code of practice.

Though certainly an improvement on the memorandum, it still would not be enough. These "short orders" may last for up to 72 hours. The patients are, by definition, disturbed, because there is an emergency. They will be there because they have either been disturbed in the community or been disturbed in the ward and tried to leave when the staff thought that it was inappropriate. The confrontation necessary for the admission or the detention may have escalated an already explosive situation. Clearly, if the patient is acutely disturbed at the moment doctors presumably have the power to give medicine to calm him, and once the common law rules are clarified there should be no serious debate about that. But what happens on, say, the second day of the 72 hour order, when the patient, improved by the effects of his first day's medicine, given because it was im-

St Mary Abbot Hospital, London W8 5 LQ

P D ROHDE, FRCPED, FRCPSYCH, consultant psychiatrist mediately necessary, now wishes to leave again but we still have not raised the necessary quorum to convert the order into an assessment or treatment order? To prevent him may mean a further escalation into another potentially dangerous confrontation. Can we continue treatment on the basis that we are still treating the original emergency, or does an interpretation of an emergency mean that we can only give immediate treatmentfor example, one injection instead of a continuing course of treatment ?

If the drafters of the Act meant us to be able to continue to treat patients throughout the 72 hours why did they specifically exclude these short orders from the provisions for consent? It is essential that the code of practice clarifies these points, and I hope that the minister will feel able to recommend continuing treatment where it is really necessary during the 72 hour order. If he does not think that this is the correct course of action it is quite possible that staff who have a responsibility to detain but no power to medicate will resort to locking doors when persuasion fails. This would be a tragedy in hospitals that have had open doors for decades.

\section{The responsible medical officer's deputy}

Section 5 represents a valiant effort to try to clear up the abuses and confusions surrounding the old section 30 and who could sign it. Unfortunately, the wording of 5(3) has added a problem of its own. The section states that the registered medical practitioner in charge of treatment may nominate one, but not more than one, other registered medical practitioner to act for him in his absence. Who is this to be ? Consider what happens in practice in a psychiatric hospital. Clearly, the consultant is the responsible medical officer when he is there. If he is on leave he will probably depute one of his junior doctors, or a fellow consultant, to act on his behalf. That will suffice in daytime, but what happens when, at night, the consultant is away and his deputy is off duty ? In practice, all hospitals probably have a consultant on call. He may be one of a number and he will also have a junior doctor on call, likewise one of a number. If the legislatures intended that the nominated deputy should be a consultant perhaps they should have said so and this would have ensured an early senior opinion for the patient-an entirely reasonable course of action in my view, particularly as the nurse has the power to detain the patient for six hours. If, on the other hand, it was intended that the duty junior doctor should be empowered to sign as nominated deputy there seems little point in having this phrase at all, since, were it just put that a registered medical practitioner had to sign, it would have been the duty junior doctor automatically.

The present wording seems to offer only three undesirable alternatives. The first is that the consultant has to nominate a different deputy every night. The second is that he remains on a permanent one in two rota with his nominated deputy. The third is that the staff at the hospital are faced with an insoluble problem when neither the responsible registered medical practitioner or his nominated deputy is available because they are both off duty. Some quite specific guidance as to how the Act should be interpreted in the code of practice would be welcome. 


\section{Public expenditure cuts in Scotland}

\section{BMA meets minister}

Representatives of the Scottish council, the craft committees, and the Scottish Joint Consultants Committee met the Scottish Minister for Health and Social Work, $\mathrm{Mr}$ John Mackay, on 16 August to express the profession's concern about the effects of the public expenditure cuts on the National Health Service. This was reported to the Scottish council when it met on 11 October. Dr Samuel McKechnie was reappointed chairman, and Dr A G R Law deputy chairman.

One of the points made at the meeting was that if effective savings were to be made in the NHS without damaging patient care there should be consultation between the government and the profession. After the meeting with the minister the Scottish chief medical officer had suggested that he and other senior officials should meet representatives of the BMA and the Scottish JCC for an informal discussion to explore the possibilities for improving cost efficiency and to explore the part that the profession might play in identifying and stimulating such improvements. This meeting had taken place on 27 Stptember.

Dr McKechnie reported that the meeting had been helpful and that several ideas had been explored, including ideas for cost effective

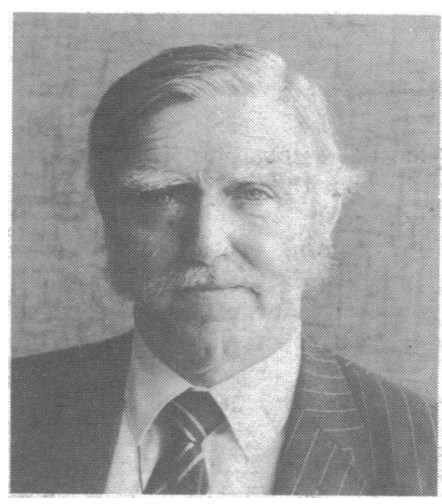

Dr Samual McKechnie. in their own areas might be improved, and to discuss these with area medical committees. It was hoped that in this way perhaps two or three methods of making savings-and thus avoiding further cuts-might be agreed between the divisions and area medical committee in each area and then, with the help of the chief administrative medical officer, put into practice.

The council approved this proposal, and it was agreed to write to honorary secretaries of divisions suggesting that they consider, in the first instance, such methods of saving as the use of hospital pharmacopoeias, generic prescribing, reuse of disposables, and transfer of follow up care after operation or treatment to general practitioners, where possible, in order to reduce the number of follow up visits to hospital clinics. Divisions have also been asked to consider, with area medical committees, other possible methods of saving, and to report back to the council with their suggestions. The chief medical officer has agreed to approach chief administrative medical officers with these proposals.

hospital systems, rationalisation of services, reduction of duplication, and coordination of hospital and community care. It had also been proposed that the best way to proceed in obtaining the views and proposals of the profession would be for BMA divisions to be asked to consider ways in which cost efficiency Organisation and management of
laboratory and radiology services

During the summer the Scottish Home and Health Department had issued a third draft continued on page 1320

Talking Point-continued from page 1318

\section{Treatment of patients in the community}

I was disappointed that the new Act contains no specific provisions for enforcing treatment outside hospital. The common clinical problem that faces me is of patients who remain in remission provided that they continue to take medicines but who relapse if they do not. Many will accept persuasion, but there are some who will not accept the need for treatment. It has always seemed to me that the "least restrictive alternative" is to keep the patient on a treatment order and allow him to remain on leave outside hospital, admitting him for one day every six months under the old section 26 for the purposes of renewing the order. I believe others like me hoped, and indeed lobbied, for a community order that would enable medicines to be given without the patient having to be technically admitted to hospital and then discharged. I have always been completely open about this practice and have discussed it on various occasions with the Mental Health Review Tribunal and have never had an appeal upheld. I am probably not unique in this use of the treatment order, but I looked in vain for some reference in the Act and memorandum to this commonsense method of management that offers a real alternative to admission to hospital.

I have been advised that it is perfectly legitimate to continue this practice on the basis that, though the patient is not detained in hospital, he is "liable to be detained," and that that justifies the use of an order specifying admission for treatment for a patient whom it is intended to treat outside hospital. Psychiatrists would feel happier if the code of practice made some comments about the management of patients who could be maintained in remission by medicines administered outside hospital under such circumstances. Unfortunately, the guardianship order is no help here. Though it conveys the power to require the patient to attend at places and at times specified for the purpose of medical treatment, etc, paragraph 45 of the memorandum makes it clear that it does not give the guardian the power to make him accept treatment. That is the real problem in my practice.

\section{Reports for the Mental Health Review Tribunal}

Less than one week after the implementation of the Mental Health Act 1983 I was called to see a patient who had been distressed to receive from the Mental Health Review Tribunal copies of long, technical reports from me and his social worker, accompanying a brief acknowledgment of his appeal. I was surprised, as he was, that these were sent unrequested, with so little comment.

If it is to be routine practice for the Mental Health Review Tribunal to send patients copies of reports opposing their appeal I think that several points follow, which may be incorporated in the code of practice. Firstly, the staff should be advised to draft reports with the knowledge that they will normally be handed to the patient. Secondly, it might become good practice for these reports to be routinely discussed with the patient before they are sent so that the contents are not such a shock when they arrive through the post. Thirdly, all wards should be advised to ensure that patients have available adequately secure places to store such sensitive documents.

\section{Reference}

${ }^{1}$ Dimond B. Consent to treatment by the mentally ill and mentally handicapped-an anomaly in the Mental Health Act 1983. Bulletin of the Royal College of Psychiatrists 1983;7:145.

(Accepted 19 October 1983) 